\title{
Nane (Mentha piperita L.) distilasyonundan arta kalan hidrosolün kek üretiminde değerlendirilmesi
}

\section{Evaluation of hydrosol remaining from peppermint (Mentha piperita L.) distillation in cake production}

\author{
Serap BERKTAŞ ${ }^{1 *}$ iD, Mustafa ÇAM ${ }^{1}$ iD \\ ${ }^{1}$ Erciyes Üniversitesi, Mühendislik Fakültesi, Gıda Mühendisliği Bölümü, Kayseri, Türkiye
}

\section{To cite this article:}

Berktaş, S. \& Çam, M. (2020). Nane (Mentha piperita L.) distilasyonundan arta kalan hidrosolün kek üretiminde değerlendirilmesi. Harran Tarım ve Gıda Bilimleri Dergisi, 24(1): 1725.

DOI: 10.29050/harranziraat.590827

Address for Correspondence: Serap BERKTAŞ

e-mail:

berktaserap@gmail.com

Received Date:

11.07.2019

Accepted Date:

20.01.2020

(c) Copyright 2018 by Harran University Faculty of Agriculture. Available on-line at www.dergipark.gov.tr/harranziraat a Creative Commons Attribution-Non
Commercial $\quad 4.0$ Intemational License.
Öz

Nane uçucu yağ ve fenolik bileşiklerce zengin tıbbi ve aromatik bir bitki olup uçucu yağ elde edilmesinden sonra geriye kalan kısımlar değerlendirilememektedir. Bu çalışmada, tıbbi nane (M. piperita L.) hidrodistilasyonu sonrası arta kalan hidrosol kısmının kek üretiminde zenginleştirme amacıyla kullanılabilme potansiyeli incelenmiştir. Bu amaçla, fenolik bileşiklerce fakir olan kek, biyoaktif bileşiklerce zengin olan nane hidrosolü ile zenginleştirilmiş ve elde edilen keklerin fizikokimyasal ve duyusal analizleri gerçekleştirilmiştir. Nanenin 1 saatlik hidrodistilasyon işlemi sonrası elde edilen hidrosolden maltodekstrin ilave edilerek ve püskürtmeli kurutucu yardımıyla kurutularak kuru hidrosol ekstraktı (KHE) elde edilmiştir. KHE \% 0.5 , \% 1 ve \% 1.5 (g/g) oranlarında kek formülasyonlarına eklenerek üretimler gerçekleştirilmiştir. Belirli oranlarda KHE içeren ve KHE içermeyen (kontrol) kek örneklerinin kuru madde, renk, toplam fenolik (TFMM), toplam flavonoid (TFM) ve antioksidan aktivite değerleri (DPPH ve ABTS) ile duyusal kabul edilebilirlikleri karşılaştırılmıştır. Ürünlere eklenen KHE miktarının artmasıyla TFMM, TFM ve antioksidan aktivite değerlerinde istatistiksel olarak anlamlı bir artışın $(p<0.05)$ olduğu saptanmıştır. KHE ile zenginleştirilen keklerin TFMM değerleri 13.60-34.03 mg GAE $100 \mathrm{~g}^{-1}$ ve DPPH değerleri 21.94-60.75 mg TE $100 \mathrm{~g}^{-1}$ arasında tespit edilmiştir. Zenginleştirilmiş kek örneklerinin genel kabul edilebilirlik puanları yakın sonuçlar göstermiştir. Duyusal analiz sonuçlarına göre kurutulmuş hidrosolün keklere eklenmesi keklerin acılık ve burukluk değerlerinin yükselmesine neden olmuştur. Nane hidrosolünün bu çalışmada gösterildiği gibi kek formülasyonlarına ilave edilebileceği ve fenolik bileşiklerce fakir diğer işlenmiş ürünlere de ilave edilme potansiyelinin olduğu belirlenmiştir.

Anahtar Kelimeler: Tıbbi nane, Hidrodistilasyon, Fenolik bileşikler, Püskürtmeli kurutucu, Kek

\section{ABSTRACT}

Peppermint is a medicinal and aromatic plant rich in essential oil and phenolic compounds and the remaining parts was not used be evaluated after extracting essential oil. In this study, it was investigated that the potential application of hydrosol fraction remaining after hydrodistilation of peppermint (M. piperita L.) in the production of cake formulation. For this purpose, the cake, poor in phenolics, was enriched with peppermint hydrosol, rich in bioactive compounds, and then physicochemical and sensory analyzes were performed. Maltodextrin was added into hydrosol which is obtained from 1 h hydrodistillation process, and then dried by spray dryer to obtain dried hydrosol extract. Dried hydrosol extract was added into cake formulations with the ratios of $0.5 \%, 1 \%$ and $1.5 \%(w / w)$. Dry matter, color, total phenolic, total flavonoid and antioxidant activity values, and sensory acceptability of enriched cake samples were compared. There were significant increases $(p<0.05)$ in total phenolic and flavonoid contents, and antioxidant activity values with increasing amount of added dried hydrosol extract into the cakes. Total phenolics were found between 13.60 - 


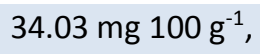

and antioxidant activities were determined between $21.94-60.75 \mathrm{mg} 100 \mathrm{~g}^{-1}$. The overall acceptability scores of the enriched cake samples were displayed similar results. Addition of dried hydrosol into cakes resulted in elevation of bitterness and astringency values of cakes. The study showed that dried hydrosol of peppermint is suitable for the production of cakes, and might be incorporated into products poor by phenolic compounds.

Key Words: Peppermint, Hydrodistillation, Phenolic compounds, Spray dryer, Cake

\section{Giriş}

Günlük olarak tükettiğimiz gıdalar ve diyetimizde yer alan besin ögeleri sağlığımız üzerinde önemli etkilere sahiptir. Yaşam standartlarının iyileşmesi ile birlikte tüketiciler besleyici değerinin yanı sıra insan sağlığına olumlu katkılar sağlayan gıdalara yönelmektedir. Gıdalara uygulanan işlemler, tüketim alışkanlıklarının değişerek yeni ürünlere yönelme isteği ve yaşam standartlarının gelişmesi gibi birtakım sebepler nedeniyle fonksiyonel gidalara olan talep artmaktadır. Bu nedenle besin içeriği yeterli ve tüketimi ile sağlık açısından fayda sağlayan fonksiyonel gıdaların geliştirilme çalışmalarına ihtiyaç duyulmaktadır (Açu, 2014; Aliyev, 2006). Birçok ülkede, yenilebilir bitkilerden elde edilen fenolik bileşikler, geniş bir hastalık grubuna karşı koruma kapasiteleri nedeniyle, içecek ve yiyecekleri zenginleştirmek için etkili bileşenler olarak kullanılmaktadırlar (Pasukamonset ve ark., 2016).

Nane (Mentha piperita L.), Akdeniz havzasında geniş bir yayılım gösteren ve on yedinci yüzyılın sonlarında İngiltere'de yetiştirilmeye başlanan tıbbi ve aromatik öneme sahip bitkilerden oluşan Lamiaceae familyasının üyeleri olan Mentha spicata ile Mentha aquatica'nın melezidir (Sinha ve Chattopadhyay, 2011). Nane kafein içermeyen bir bitki olması ve yapraklarında \% 1.2 ila \% 3.9 oranında bulunan uçucu yağı dolayısıyla bitki çayı olarak yoğun şekilde tüketilmektedir. Nane yaprakları ve uçucu yağları antioksidan, antimikrobiyal ve immüno-modülasyon aktiviteleri de dahil olmak üzere faydalı etkileri nedeniyle gıdalar, farmasötik formülasyonlar ve kozmetikler için de kullanılmaktadır (Jeong ve ark., 2018). Geleneksel olarak çeşitli kültürlerde kullanımı çok eskilere dayanan nanenin son dönem bilimsel çalışmalarla antioksidan,

antitümör, antimikrobiyal ve antialerjenik gibi birtakım biyolojik aktivitelere sahip olduğu, ayrıca sindirim sistemi üzerinde faydalı etkileri olduğu belirlenmiştir. Geleneksel olarak gastrointestinal rahatsızlıklarını gidermede önerilen nanenin uçucu yağ fraksiyonunun huzursuz bağırsak sendromu için güvenli ve etkili bir kısa süreli tedavi edici özelliğinin olduğu belirlenmiştir (Dualı, 2010). Literatür taramasında nane gibi tıbbi bitkilerin biyolojik potansiyeline olan ilginin arttığı görülmektedir

Aromatik bitkilerin distilasyonu sonrası uçucu yağ, distile edilmiş biyokütle ve artık su (hidrosol) elde edilmektedir (D'Amato ve ark., 2018). Hidrosollerin aromatik profili, hidrofobik, suda çözünmeyen izoprenoit bileşiklerinin (hidrokarbonlar) bulunmamasından dolayı, ilgili uçucu yağlardan önemli ölçüde farklı olabilir (Rajeswara Rao, 2013). Hidrosoller, bitkilerden uçucu yağ elde etmek için kullanılan hidrodistilasyon işlemleri sonrasında elde edilen ikincil ürünlerdir. Geleneksel kullanımda hidrosoller Akdeniz ülkelerinde geleneksel tıpta serinletici içecek olarak kullanılmaktadır. Hidrosollerin son zamanlarda fark edilen özellikleri ise hem in vitro hem de model gıdalarda, özellikle bakteri ve mantarlar dahil olmak üzere patojenik ve bozulma mikroorganizmalarına karşı antimikrobiyal etkinlik sergilemeleridir (D'Amato ve ark., 2018). Hidrosoller iz miktarda uçucu yağ ve pek çok suda çözünür bileşenler içeren oldukça değerli kompleks karışımlardır (Fleisher ve Fleisher, 1991).

Tüketime hazır yiyecekler tüm dünyada tüketicilerin yeme davranışlarındaki değişiklikler sebebiyle rağbet ettikleri ürün gruplarıdır. Bununla birlikte, tüketicilerin diyet lifi açısından zengin veya biyoaktif bileşiklerce zengin ürünler gibi sağlığa fayda sağlayan ürün gruplarına olan yönelimleri de artmaktadır. Fırıncılık ürünlerinin tüketicilerce 
oldukça fazla rağbet görmeleri nedeniyle biyoaktif bileşenlerin fırıncılık ürünlerine ilave edilmesi ve bu sayede tüketiciye ulaştırılması mümkün gözükmektedir (Kim ve ark., 2012). Unlu mamuller içerisinde önemli yeri olan kek, genellikle un, su, şeker, kabartıcılar ve yumurta gibi bileşenlerin uygun oranlarda karıştırılarak elde edilen hamurun pişirilmesi suretiyle elde edilen bir gıda ürünüdür (Alrefaire ve Bostan, 2017). Kek, tüm dünyadaki tüketiciler için popülerdir ve daha fazla biyoaktif bileşik tüketmenin iyi bir yolu olabilir (Mau ve ark., 2017; Drabińska ve ark., 2018). Kamiloglu ve ark. (2017) keklere siyah havuç posası ekleyerek keklerde zenginleştirme işlemi yapmış ve kekin besin değerini artırmışlardır. Aynı şekilde Mau ve ark. (2017) keklere siyah pirinç tozu ekleyerek kekin özelliklerinde anlamlı artışlar tespit etmişlerdir. Bu nedenle, nane hidrosolünün kek formülasyonları içerisine ilave edilerek yeni bir kek üretimi formülasyonu geliştirmenin faydalı olabileceği öngörülmüştür.

Nane uçucu yağı, yaprağının çok az bir miktarını temsil etmekte ve ekstre edildikten sonra geriye değerlendirilmeyen biyolojik öneme sahip maddeler içeren yan ürünler kalmaktadır. Nane distilasyonu sonrası arta kalan materyalin değerlendirilmemesi hem ülke ekonomisi hem de gıda sektörü için önemli bir ekonomik kayıptır. Nane distilasyonu sonrası kalan hidrosol fenolik bileşikler gibi biyoaktif maddeler içerdiğinden gıda, ilaç gibi farklı sektörlerde yardımcı madde olarak kullanım olanakları araştırılmalıdır. Bu çalışmada nane distilasyon artık ürünü olan hidrosolün değerlendirilip ekonomiye kazandırılarak, sağlık üzerine olumlu etkilere sahip fonksiyonel ürünlerin elde edilmesi amaçlanmıştır.

\section{Materyal ve Metot}

\section{Materyal}

2016 temmuz ayında hasat edilmiş olan nane (M. piperita), kurutulmuş formda Erciyes Üniversitesi Tarımsal Araştırma Merkezi'nden, sakkaroz (Balküpü), emülgatör (mono- ve digliserit), maltodekstrin (13-17 DE), un (Selva), yumurta akı tozu, kabartma tozu (D. Oetker), yağ
(Becel \% 59 yağlı bitkisel margarin), yağsız süt tozu (Pınar), içme suyu ve tuz Kayseri yerel piyasasından tedarik edilmiştir.

\section{Metot}

Hidrodistilasyon işlemi ve kurutulmuş hidrosollerin elde edilmesi

Nane hidrosolünün elde edilmesi amacıyla hidrodistilasyon işlemi gerçekleştirilmiştir. $\mathrm{Bu}$ amaçla, $50 \mathrm{~g}$ kurutulmuş nane yaprağı $500 \mathrm{ml}$ distile su ile Clevenger hidrodistilasyon aparatında (ildam-1000 ml) 1 saat distile edilmiştir. Nane esansiyel yağı ayrıldıktan sonra kalan sulu ekstrakt (hidrosol) filtre kağıdı kullanılarak filtre edilmiştir. Hidrosoller 1:1 oranında (kuru madde) maltodekstrin ile homojeneze edilerek $150{ }^{\circ} \mathrm{C}$ ' de kurutucu giriş sıcaklığında püskürtmeli kurutucuda (B-290, BUCHI, İsviçre) kurutularak KHE elde edilmiştir.

\section{Kek üretimi}

KHE ile zenginleştirilen kekler Çizelge $1^{\prime}$ de verilen formülasyonlar kullanılarak fanlı fırında (Albeni, Simfer, Türkiye) üretilmiştir. KHE içermeyen kek B1, formülasyondaki unun ağırlıkça $\%$ 0.5' i KHE fenolik bileşiği olan kek B2, \% 1' i olan kek B3 ve \% 1.5' i KHE fenolik bileşiği olan kek B4 olacak şekilde üretimler gerçekleştirilmiştir. Kek formülasyonu hazırlanırken keklerin toplam kuru madde içeriklerini dengelemek adına \% 1,5 KHE içeren kek örneğindeki KHE miktarına denk gelecek şekilde diğer kek formülasyonları maltodekstrin ile tamamlanmıştır. Kek hamurunu hazırlamak için öncelikle formülasyonun katı bileşenleri olan un, hamur kabartma tozu, tuz, sakkaroz, süt tozu, yumurta akı tozu, KHE ve maltodekstrinin mikserde (K $8160 \mathrm{P}$ in love, Arçelik, Türkiye) 85 rpmde 1 dakika karıştırılmıştır. Erimiş yağ ve içme suyunun karışıma eklenmesinin ardından karışım 140 rpmde 2 dakika boyunca karıştırılarak hamur elde edilmiş ve tek kullanımlık kek kalıplarına aktarılarak önceden ısıtılmıs $175{ }^{\circ} \mathrm{C}$ fırında 25 dakika süreyle pişirilmiştir. Pişirmeden sonra kekler, kurumalarını önlemek için kapatılarak kodlanmış olan plastik torbalara yerleştirilmeden önce ortam ısısına gelmeleri için soğumaya bırakılmıştır. 
Çizelge 1. Kek örneklerinin formülasyonu (Sakiyan ve ark., 2011)

Table 1. Formulation of cake samples (Sakiyan et al., 2011)

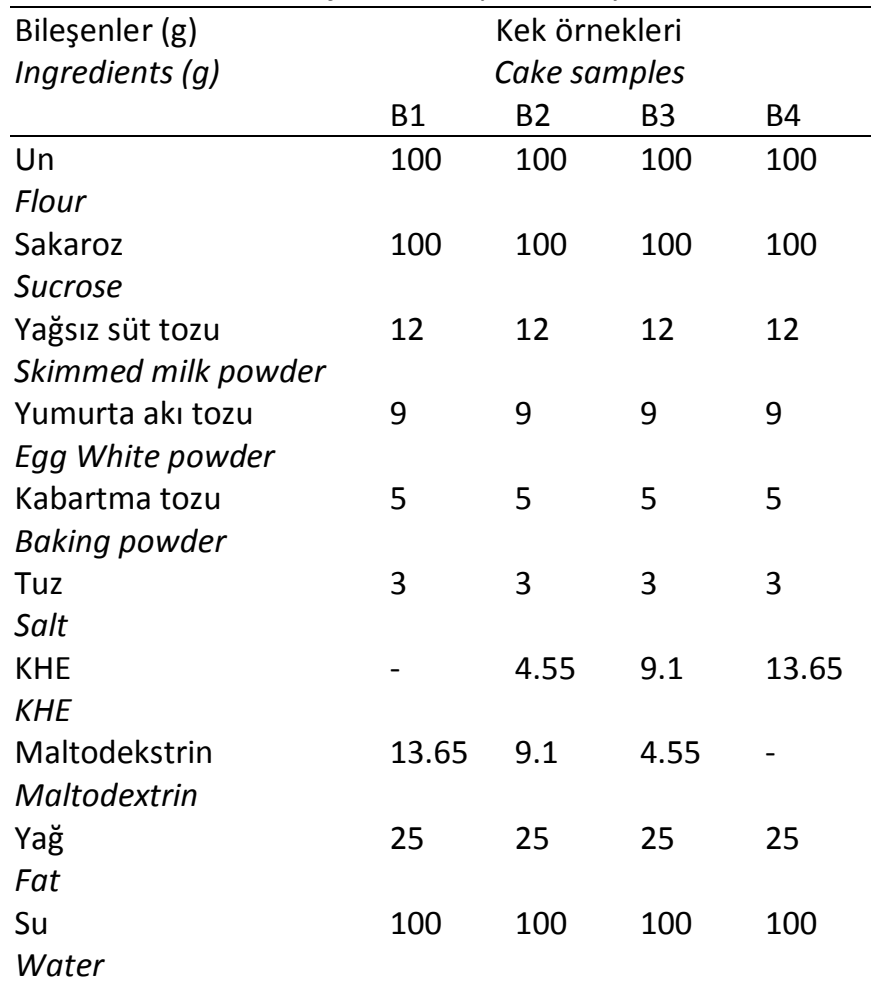

*B1: Kontrol örneği, B2: \% 0.5 KHE içeren kek, B3: \% $1 \mathrm{KHE}$ içeren kek, B4: \% 1.5 KHE içeren kek, KHE: Kuru hidrosol ekstraktı.

${ }^{*} B 1$ : Control sample, B2: Cake with 0.5\% KHE, B3: Cake with 1\% KHE, B4: Cake with 1.5\% KHE, KHE: Dry hydrosol extract.

\section{Fizikokimyasal analizler}

Kek örneklerinden 10' ar gram tartılarak $90 \mathrm{ml}$ distile su ile 10 dakika homojenize edilmiş ve $\mathrm{pH}$ değerleri bir $\mathrm{pH}$ metre vasıtasıyla (HANNA instruments, ABD) belirlenmiştir (Baltacıoğlu ve Uyar, 2017). Toplam asitlik değeri $0.1 \mathrm{~N} \mathrm{NaOH}$ ile volümetrik-potansiyometrik titrasyon yöntemiyle sitrik asit cinsinden belirlenmiştir. Ürünlerin rengi, 'L', 'a', 'b' değerleri bakımından bir kromometre ile (CR-5, Konica Minolta, Japan) kaydedilmiştir. Keklerin iç ve dış renk değerleri ayrı ayrı ölçülmüştür. Nem tayini ise $105{ }^{\circ} \mathrm{C}$ 'de etüvde (DT104, GEMO, Türkiye) 24 saat örneklerin kurutulmasıyla gerçekleştirilmiştir.

\section{Fenolik bileşiklerin ekstraksiyonu}

Kek örneklerinden 10 gram tartılarak $100 \mathrm{ml}$ aseton eklenmiş ve $40{ }^{\circ} \mathrm{C}^{\prime}$ de 1 saat süre ile çalkalamalı su banyosunda (ST30, NÜVE, Türkiye) ekstraksiyon işlemi gerçekleştirilmiştir. Ekstrakt kaba filtre kağıdından süzülerek $40^{\circ} \mathrm{C}$ de vakumlu evaporatörde (Value G1, Heidolph Hei-Vap,
Almanya) asetonu uzaklaştırılmış ve $20 \mathrm{ml}^{\prime}$ ye metanol:su (1:1) ile hacmi tamamlanmıştır (Çam ve ark., 2013). Elde edilen ekstrakt toplam fenolik ve flavonoid içeriği ile antioksidan aktivitelerin belirlenmesinde kullanılmıştır.

\section{Toplam fenolik ve flavonoid içeriği}

Örneklerin toplam fenolik içeriği Folin-Ciocalteu (FC) reaktifi ile Singleton ve Rossi. (1965) tarafından geliştirilip Li ve ark. (2006) tarafından modifiye edilen metot kullanılarak spektrofotometrik olarak belirlenmiş ve sonuçlar fenolik bir bileşik olan gallik asit eşdeğeri olarak verilmiştir. Örneklerin toplam flavonoid madde içeriği Zhinsen ve ark. (1999) metodu kullanılarak spektrofotometrik olarak belirlenmiş ve sonuçlar kateşin eşdeğeri olarak verilmiştir.

\section{Antioksidan aktivite tayinleri}

Örneklerin antioksidan aktiviteleri DPPH ve ABTS metotlarına göre belirlenmiştir. DPPH antiradikal aktivite tayini 1,1-difenil-2-pikrilhidrazil (DDPH) radikalini indirgeme aktivitesi kullanarak spektrofotometrik yöntemle belirlenmiştir (Brand-Williams ve ark., 1995).

ABTS antioksidan aktivite tayininde ise $R e$ ve ark. (1999) metodu kullanılmıştır. ABTS radikal çözeltisinin absorbansı $734 \mathrm{~nm}$ de $0.700 \pm 0.005^{\prime}$ i verecek şekilde fosfat tamponu (PBS) ile seyreltilerek ayarlanmıştır. Ekstraktlardan 20, 40, 60, $80 \mu \mathrm{l}$ alınarak $2 \mathrm{ml}$ hacimli plastik küvetlere konulmuş ve üzerine absorbansı ayarlanan $2 \mathrm{ml}$ radikal çözeltisi eklenerek karanlıkta 6 dakika bekletilmiştir. Örneklerin antioksidan aktivite değerleri mg troloks $\mathrm{g}^{-1}$ örnek cinsinden verilmiştir.

\section{Duyusal analizler}

Keklerin duyusal açıdan tercih dereceleri hedonik skala testi ile belirlenmiştir. Eğitimsiz gönüllü 70 panelist tarafından gerçekleştirilen duyusal değerlendirmede panelistlerden 9 noktadan oluşan bir hedonik ölçekte (1: çok kötü, 5: orta, 9: mükemmel) tercih derecesine göre puanlamaları istenmiştir. Hedonik duyusal değerlendirme Erciyes Üniversitesi Mühendislik Fakültesi öğrencileri tarafından Gıda Mühendisliği 
bölüm duyusal laboratuvarında (Kayseri, Türkiye) gerçekleştirilmiştir. Kekler hacim, koku, lezzet, tatlılık, yapı/tektür, acılık, burukluk, yumuşaklık, gözenek homojenliği ve büyüklüğü, kabuk rengi, iç renk ve genel beğeni açısından değerlendirilmiştir. Değerlerin ölçeği "son derece beğenmemek" (puan 1) ile "son derece beğenmek" (puan 9) arasında değişmektedir. Numunelerin duyusal analizleri üretimden bir gün sonra gerçekleştirilmiştir. Örnekler, üç basamaklı rasgele sayılarla kodlanarak rastgele sırayla servis edilen beyaz plastik tabaklarda sunulmuştur. Tüketicilere numuneleri değerlendirdikten sonra kalıntı etkisini en aza indirmek için ağızlarını numuneler arasında suyla çalkalamaları istenmiştir.

\section{istatistiksel analiz}

Tüm veriler İstatistiksel Analiz Sistemi yazılım paketi (SPSS 17.0.1 Inc., Chicago, III, USA) kullanılarak bir varyans analizine (ANOVA) tabi tutulmuştur. ikiden fazla grup karşılaştırmaları gerçekleştirilirken verilerin normalliğinin sağlandığı durumlarda tek yönlü varyans analizi, verilerin normal dağılmadığı durumlarda ise Kruskal-Wallis testi kullanılmıştır. Gruplar arasındaki farklılıklar varyansların homojen dağılması halinde Tukey testi, homojenliğinin sağlanmadığı durumlarda ise Dunnett T3 testi kullanılarak değerlendirilmiştir. Gruplara ait veriler değerlendirilirken $p$ 'anlamlılık' değeri $(p<0.05)$ göz önünde bulundurularak grup ortalamaları arasındaki fark test edilmiştir.

\section{Araştırma Bulguları ve Tartışma}

\section{Keklerin fizikokimyasal özellikleri}

Farklı oranlarda KHE ile zenginleştirilen keklerin bazı fizikokimyasal özellikleri Çizelge 2' de verilmiştir. Kek grupları arasında (B1, B2, B3, B4) tüm fizikokimyasal özellikler açısından fark istatistiksel olarak anlamlı bulunmuştur $(p<0.05)$. Keklerdeki KHE oranının artması ile birlikte kuru madde ve toplam asitlik değerlerinin anlamlı şekilde arttığı görülürken, $\mathrm{pH}$ değerlerinin azaldığı görülmektedir $\quad(p<0.05)$ Keklerdeki fenolik içeriğinin artması sonucu asitliğin arttığı dolayısıyla da pH değerlerinin düştüğü tespit edilmiştir. Baltacıoğlu ve Uyar. (2017) kabak tozunun kek üretimindeki potansiyelini inceledikleri çalışmalarında kek örneklerininin asitlik değerlerinin kabak tozu ilavesiyle arttığını ve bu durumun kabak tozunun $\mathrm{pH}$ değerinin düşük olmasından kaynaklandığı belirtmişlerdir. Keklerin rengi KHE eklenmesi ile değişmektedir. KHE ile zenginleştirilmiş keklerin kabuk $L^{*}$ aydınlık değerleri ve $b^{*}$ sarılık değerleri kontrole göre azalırken $a^{*}$ kırmızılık değerleri anlamlı şekilde artmıştır $(p<0.05)$. Illave edilen KHE miktarı attıkça keklerin rengi daha koyu ve daha kırmızımsı hale gelmektedir. Lu ve ark. (2010) yeşil çay ile zenginleştirdikleri keklerdeki yeşil çay tozunun artmasına bağlı olarak keklerin koyu renginde artış tespit ederken kırmızılık ve sarılık değerlerinin azaldığını belirlemişlerdir. Keklerdeki renk değişikliğinin çay pigmentleri ve polifenol bileşiklerinin oksidasyon reaksiyonuna girmesi ve sukrozun pişirme sırasında karamelleşmeye katılmış olması ile ilgili olabileceğini ileri sürmüşlerdir. Çalışmamızda, kontrol örneğinin (B1) rengi zenginleştirilen keklere kıyasla daha açık ve daha sarı renkli olduğu tespit edilmiştir. Bu durumda nane hidrosolünün kahverengimsikırmızı renginin kek örneklerinin rengine de yansıdığı görülmektedir. Dolayısıyla keke katılan KHE keklerin daha kırmızımsı renkte olmalarına sebep olmuştur. Ayrıca, keklerin kabuk değerlerindeki koyuluğun iç renge kıyasla daha fazla olduğu ve bu durumun ısıyla direk temasta olan kabukta meydana gelecek olan koyuluğun şekerlerin karamelizasyonu ve maillard reaksiyonundan ileri geleceği öngörülmektedir (Gomez ve ark., 2008). Ürünün pişirilmesi göz önüne alındığında esmerleşme reaksiyonlarının ve buna ilaveten, kek bileşimine undan farklı bir tozun eklenmesinin eklenen tozun rengi ve tipine göre kekin rengini etkileyeceği bildirilmektedir (Shin ve ark., 2007). 
Çizelge 2. Keklerin bazı fizikokimyasal özellikleri

Table 2. Some physicochemical properties of cakes

\begin{tabular}{|c|c|c|c|c|}
\hline $\begin{array}{l}\text { Özellikler } \\
\text { Properties }\end{array}$ & & & & \\
\hline & B1 & B2 & B3 & B4 \\
\hline $\begin{array}{l}\text { Toplam kuru madde (\%) } \\
\text { Total dry matter (\%) }\end{array}$ & $79.92 \pm 0.03^{a}$ & $81.34 \pm 0.01^{b}$ & $82.13 \pm 0.33^{b c}$ & $82.60 \pm 0.37^{c}$ \\
\hline $\begin{array}{l}\text { Toplam asitlik (\%) } \\
\text { Acidity (\%) }\end{array}$ & $0.14 \pm 0.01^{\mathrm{a}}$ & $0.16 \pm 0.01^{a}$ & $0.21 \pm 0.01^{b}$ & $0.22 \pm 0.01^{b}$ \\
\hline $\begin{array}{l}\text { pH değeri } \\
\mathrm{pH} \text { value }\end{array}$ & $7.29 \pm 0.14^{\mathrm{a}}$ & $7.11 \pm 0.14^{b}$ & $6.93 \pm 0.14^{c}$ & $6.87 \pm 0.14^{d}$ \\
\hline $\begin{array}{l}\mathrm{L}^{*} \text { (kabuk) } \\
L^{*} \text { (top) }\end{array}$ & $58.41 \pm 1.92^{a}$ & $42.74 \pm 1.92^{b}$ & $46.53 \pm 0.22^{b}$ & $43.43 \pm 2.11^{b}$ \\
\hline $\begin{array}{l}\text { a* (kabuk) } \\
a^{*} \text { (top) }\end{array}$ & $6.79 \pm 0.05^{a}$ & $14.33 \pm 0.08^{b}$ & $11.59 \pm 1.26^{b}$ & $11.79 \pm 1.04^{b}$ \\
\hline $\begin{array}{l}\mathrm{b}^{*} \text { (kabuk) } \\
b^{*} \text { (top) }\end{array}$ & $36.76 \pm 0.49^{a}$ & $27.37 \pm 0.19^{b}$ & $19.01 \pm 1.71^{\mathrm{c}}$ & $19.30 \pm 0.43^{c}$ \\
\hline $\begin{array}{l}L^{*} \text { (iç) } \\
L^{*} \text { (inner) }\end{array}$ & $73.36 \pm 1.44^{a}$ & $60.74 \pm 3.40^{b}$ & $46.50 \pm 3.13^{c}$ & $47.11 \pm 4.01^{c}$ \\
\hline $\begin{array}{l}\text { a* (iç) } \\
a^{*} \text { (inner) }\end{array}$ & $0.37 \pm 0.09^{a}$ & $4.18 \pm 0.54^{b}$ & $4.24 \pm 0.09^{b c}$ & $6.33 \pm 0.84^{c}$ \\
\hline $\begin{array}{l}\mathrm{b}^{*} \text { (iç) } \\
b^{*} \text { (inner) }\end{array}$ & $18.37 \pm 0.08^{a}$ & $22.16 \pm 0.25^{\mathrm{ab}}$ & $19.17 \pm 0.97^{a}$ & $24.62 \pm 4.33^{b}$ \\
\hline
\end{tabular}

*B1: Kontrol örneği, B2: \% 0.5 KHE içeren kek, B3: \% 1 KHE içeren kek, B4: \% $1.5 \mathrm{KHE}$ içeren kek. ${ }^{* *}$ Çizelge üzerindeki değerler verilerin ortalama \pm standart sapma değerlerini ifade etmektedir. Aynı satır içerisindeki harfler tek yönlü varyans analizi sonucunda varyansların homojenliğinin sağlandığı gruplarda Tukey testi, sağlanamadığı gruplarda ise Dunnett T3 testi sonuçlarını ifade etmekte olup farklı harfler örnek ortalamaları arasında fark olduğunu $(\mathrm{p}<0.05)$ belirtmektedir. ${ }^{* * *}$ Titrasyon asitliği değerleri sitrik asit cinsinden verilmiştir.

Keklerin toplam fenolik (TFMM) ve flavonoid içerikleri (TFM)

Keklerin TFMM (mg GAE $100 \mathrm{~g}^{-1}$ kek) ve TFM (mg KE $100 \mathrm{~g}^{-1}$ kek) değerleri Şekil 1' de gösterilmiştir. KHE ile zenginleştirilen keklerin TFMM ve TFM değerleri açısından fark istatistiksel olarak anlamlı bulunmuştur $(p<0.05)$. Keklerdeki KHE oranı arttıkça TFMM ve TFM' nın arttığı, bu durumun keklerdeki KHE oranının artmasına bağlı olarak fenolik içeriğinin artmasından kaynaklandığı belirlenmiş̧ir. En yüksek TFMM ve TFM değerlerine \% 1.5 KHE ile zenginleştirilmiş kek (B4) örneğinde ulaşılırken en düşük değere $\mathrm{KHE}$ içermeyen kontrol keki örneğinde (B1) ulaşılmıştır. Mau ve ark. (2017)' un siyah pirinç tozu ilaveli keklerinde TFMM' nın kontrol grubuna göre anlamlı şekilde yüksek bulunduğunu tespit etmişlerdir. Kamiloglu ve ark. (2017) keke polifenol kaynağı olarak siyah havuç posası ile keklerdeki TFMM değerlerinde anlamlı artışlar yakalayarak kekin besin değerini artırmışlardır.

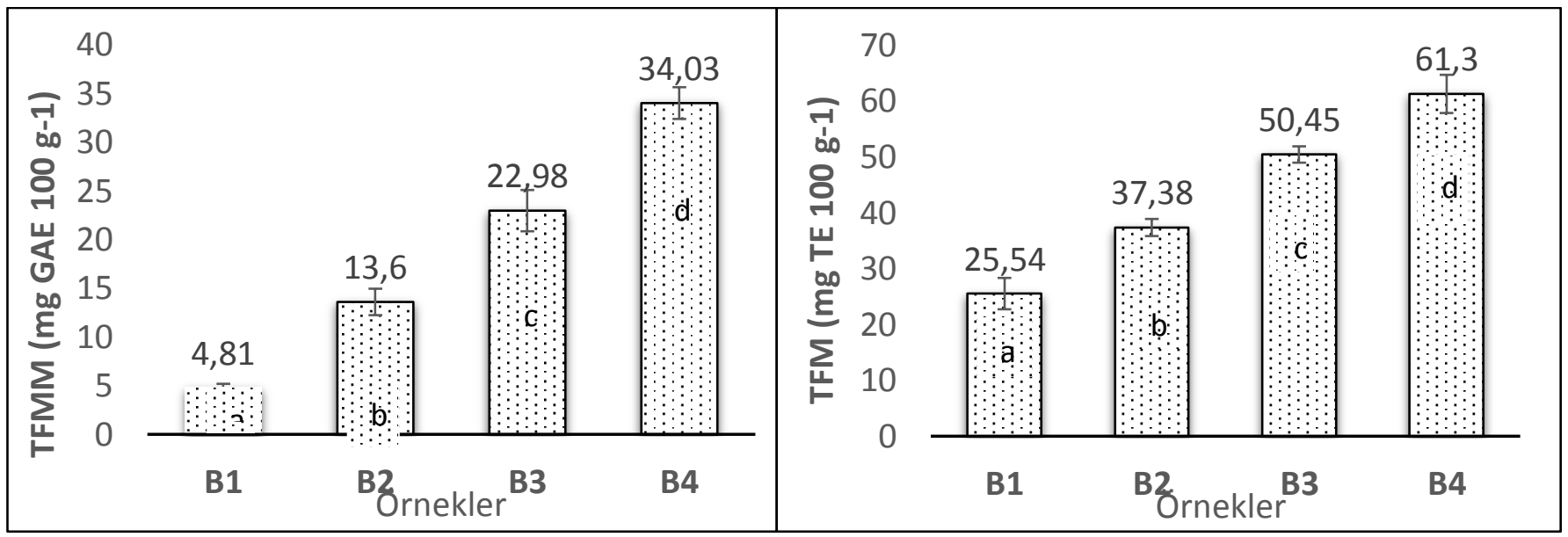

Şekil 1. Keklerin TFMM ve TFM içerikleri

Figure 1. TFMM and TFM contents of cakes

${ }^{*}$ B1: Kontrol örneği, B2: \% 0.5 KHE içeren kek, B3: \% 1 KHE içeren kek, B4: \% 1.5 KHE içeren kek, GAE: gallik asit eşdeğeri, KE: kateşin eşdeğeri. ${ }^{* *}$ Çizelge üzerindeki değerler verilerin ortalama \pm standart sapma değerlerini ifade etmektedir. Aynı satır içerisindeki harfler varyansların homojenliğinin sağlandığı gruplarda Tukey testi, sağlanamadığı gruplarda Dunnett T3 testi sonuçlarını ifade etmekte olup farklı harfler örnek ortalamaları arasında fark olduğunu $(p<0.05)$ belirtmektedir. 


\section{Keklerin antioksidan aktiviteleri}

Nane yağı izolasyonu sonrası kalan hidrosollerin zenginleştirilen keklerin DPPH ve ABTS antioksidan aktiviteleri üzerindeki etkisini gösteren değerler Şekil 2' de verilmiştir. Keklerdeki fenolik maddenin artması ile orantılı olarak antioksidan aktivite değerlerinin arttığı ve örnekler arasındaki farkın istatistiksel olarak önemli olduğu tespit edilmiştir $(p<0.05)$. En yüksek antioksidan aktivite değerinin en fazla oranda KHE içeren B4 örneğinde olduğu görülmektedir. Fenolik bileşikler antioksidan aktivite sergilediklerinden dolayı fenolik içeriğinin artışı nedeniyle antioksidan aktivite de artmıştır. Kamiloglu ve ark. (2017) siyah havuç posasıyla zenginleştirdikleri keklerin ABTS değerlerini zenginleştirilmiş keklerde 143-178 mg TE $100 \mathrm{~g}^{-1}$ olarak belirlerken, DPPH değerlerini 56$153 \mathrm{mg}$ TE $100 \mathrm{~g}^{-1}$ olarak belirlemişler ve hiç posa içermeyen kek grubundan anlamlı şekilde yüksek bulgulara ulaşmışlardır. Mau ve ark. (2017) siyah pirincin keklerin antioksidan aktivitesini büyük ölçüde arttırdığını ve hem toplam fenollerin hem de ekstraktlardaki toplam antosiyaninlerin değerleriyle anlamlı derecede korelasyonlu olduğunu belirlemişlerdir. Elde edilen verilerde, toplam fenollerin zenginleştirilmiş kek numunelerinin antioksidan aktivitesi üzerinde güçlü bir etkisi olduğu sonucuna ulaşılmıştır.

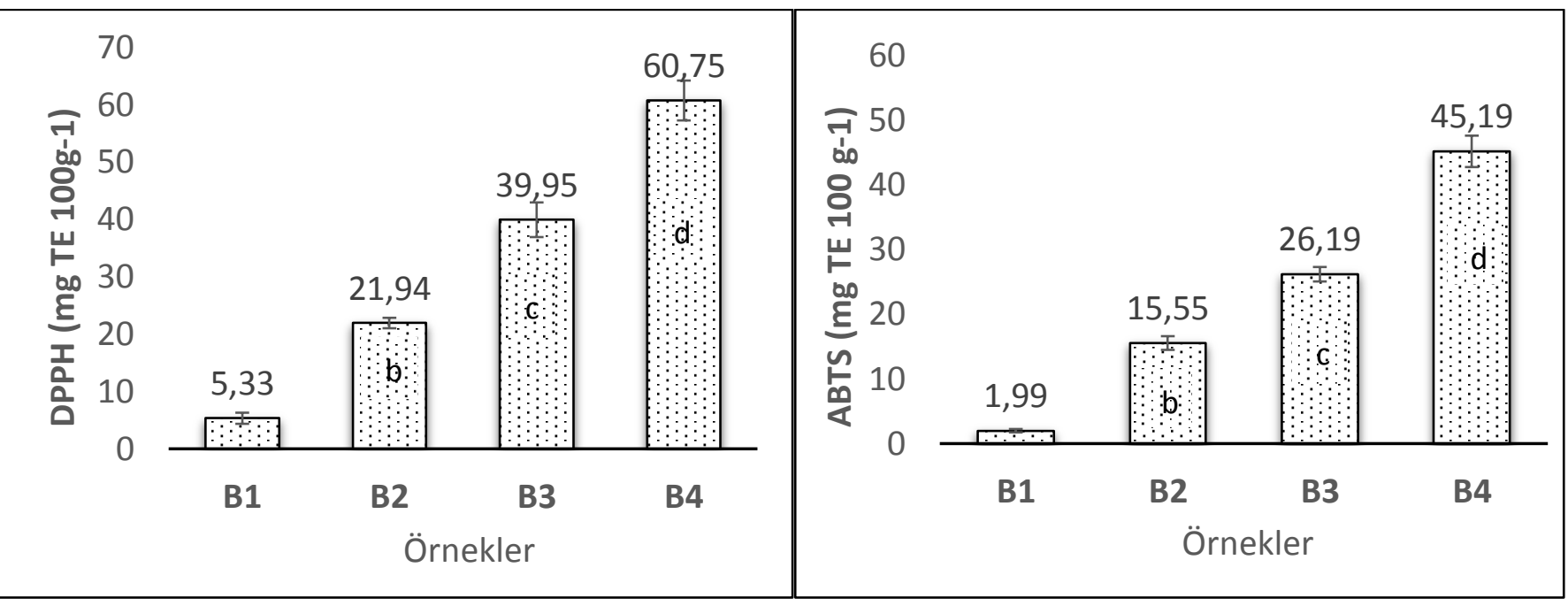

Şekil 2. Keklerin antioksidan aktiviteleri

Figure 2. Antioxidant activities of cakes

${ }^{*}$ B1: Kontrol örneği, B2: \% 0.5 KHE içeren kek, B3: \% 1 KHE içeren kek, B4: \% 1.5 KHE içeren kek. TE: troloks eşdeğeri. ${ }^{* *}$ Çizelge üzerindeki değerler verilerin ortalama \pm standart sapma değerlerini ifade etmektedir. Aynı satır içerisindeki harfler Dunnett T3 testi sonuçlarını ifade etmekte olup farklı harfler örnek ortalamaları arasında fark olduğunu $(p<0.05)$ belirtmektedir.

\section{Keklerin duyusal özellikleri}

Keklerin duyusal kabul edilebilirlikleri Çizelge 2'de verilmiştir. Keklerdeki KHE içeriğinin artmasıyla duyusal özellikler açısından beğeninin azaldığı ve örnekler arasında bazı özellikler açısından istatistiksel olarak anlamlı farklılıkların bulunduğu $(p<0.05)$ belirlenmiştir. Panelistler kontrol numuneleri ile zenginleştirilen kekler arasındaki farkı hacim ve gözenek homojenliği özellikleri açısından belirleyememiştir ( $p>0.05$ ). Dolayısıyla, KHE' nın eklenmesinin keklerin kabarmasına olumsuz bir etkisinin olmadığı tespit edilmiştir. Koku, lezzet, tatlılı, yapı/tekstür, acılık, yumuşaklık ve genel beğeni açısından en beğenilen örneğin kontrol (B1) grubu olduğu belirlenmiştir.
Acılık ve burukluğun hissedilebilirliği keklerdeki KHE miktarının artmasına bağlı olarak giderek artarken, lezzet ve kokunun beğenirliğinin ise giderek azaldığı belirlenmiştir. Bu durumun nane fenoliklerinden ileri gelen acı ve buruk tadın giderek artmasından kaynaklandığı görülmektedir. Zenginleştirilen keklerin tatılıkları değerlendirildiğinde ise nane fenoliklerinin baskın olmasının tatlılığın algılanabilirliğini düşürdüğü belirlenmiştir. Kabuk rengi ve iç renk olarak kontrol (B1) ve \% 0.5 KHE ile zenginleştirilmiş kekin (B2) aynı beğeniyi aldığı ve dolayısıyla keklerin renginde $\mathrm{KHE}$ oranının \% 0.5 düzeyine kadar istenildiği tespit edilmiştir. Buna ek olarak genel beğeni açısından zenginleştirilmiş kekler arasında 
(B2, B3, B4) anlamlı bir farkın olmadığı belirlenmiştir ( $p>0.05)$. Nane fenolikleri kaynaklı buruk ve acı tadın artışı, zenginleştirilmiş keklerin düşük duyusal skorlar almalarına neden olmuştur. Genel itibariyle en yüksek duyusal skorları kontrol grubu almış olsada zenginleştirilmiş keklerin beğeni puanları ortalama değerin üzerinde veya yakın değerlerde olduğu görülmektedir. $\mathrm{Bu}$ duyusal sonuçlar, zenginleştirilmiş keklerde \% 1.5' e varan kuru hidrosol tozu eklenmesinin duyusal açıdan kabul edilebilir düzeyde olduğunu göstermiştir.

Çizelge 2. Keklerin duyusal analiz sonuçları

Table 2. Sensory analysis results of cakes

\begin{tabular}{|c|c|c|c|c|}
\hline $\begin{array}{l}\text { Duyusal özellikler } \\
\text { Sensory properties }\end{array}$ & & $\begin{array}{l}\mathrm{K} \\
\mathrm{C}\end{array}$ & & \\
\hline & B1 & B2 & B3 & B4 \\
\hline $\begin{array}{l}\text { Hacim } \\
\text { Volume }\end{array}$ & $6.47 \pm 1.73^{a}$ & $6.45 \pm 1.81^{a}$ & $6.18 \pm 1.91^{a}$ & $6.31 \pm 1.97^{a}$ \\
\hline $\begin{array}{l}\text { Koku } \\
\text { Odour }\end{array}$ & $6.81 \pm 1.86^{\mathrm{a}}$ & $5.99 \pm 2.15^{\mathrm{ab}}$ & $5.72 \pm 2.42^{b}$ & $5.76 \pm 2.18^{b}$ \\
\hline $\begin{array}{l}\text { Lezzet } \\
\text { Flavor }\end{array}$ & $6.11 \pm 2.06^{\mathrm{a}}$ & $5.12 \pm 2.29^{\mathrm{ab}}$ & $4.84 \pm 2.50^{\mathrm{bc}}$ & $4.15 \pm 2.37^{c}$ \\
\hline $\begin{array}{l}\text { Tatlılık } \\
\text { Sweetness }\end{array}$ & $6.39 \pm 2.19^{a}$ & $5.26 \pm 2.36^{b}$ & $5.18 \pm 2.41^{b}$ & $4.97 \pm 2.62^{b}$ \\
\hline $\begin{array}{l}\text { Yapı/tekstür } \\
\text { Texture }\end{array}$ & $6.41 \pm 1.82^{a}$ & $5.55 \pm 2.09^{\mathrm{ab}}$ & $5.64 \pm 2.00^{\mathrm{ab}}$ & $5.30 \pm 2.16^{b}$ \\
\hline $\begin{array}{l}\text { Acllık } \\
\text { Bitterness }\end{array}$ & $8.08 \pm 1.57^{a}$ & $6.86 \pm 2.26^{b}$ & $5.84 \pm 2.64^{b c}$ & $5.53 \pm 2.85^{c}$ \\
\hline $\begin{array}{l}\text { Burukluk } \\
\text { Sourness }\end{array}$ & $7.34 \pm 2.08^{a}$ & $6.58 \pm 2.29^{a}$ & $5.36 \pm 2.53^{b}$ & $5.23 \pm 2.67^{b}$ \\
\hline $\begin{array}{l}\text { Yumuşaklık } \\
\text { Softness }\end{array}$ & $6.39 \pm 2.02^{a}$ & $5.22 \pm 2.27^{b}$ & $5.31 \pm 2.26^{b}$ & $4.73 \pm 2.20^{b}$ \\
\hline $\begin{array}{l}\text { Gözenek homojenliği } \\
\text { Pore homogeneity }\end{array}$ & $6.81 \pm 1.83^{a}$ & $5.99 \pm 1.93^{a}$ & $6.30 \pm 2.05^{a}$ & $6.16 \pm 2.08^{a}$ \\
\hline $\begin{array}{l}\text { Kabuk rengi } \\
\text { Shell color }\end{array}$ & $7.19 \pm 1.70^{a}$ & $6.99 \pm 1.79^{a}$ & $6.71 \pm 1.72^{\mathrm{ab}}$ & $6.11 \pm 2.09^{b}$ \\
\hline $\begin{array}{l}\text { İç renk } \\
\text { interior color }\end{array}$ & $7.16 \pm 1.94^{\mathrm{a}}$ & $6.76 \pm 1.74^{\mathrm{a}}$ & $6.46 \pm 1.80^{\mathrm{ab}}$ & $5.78 \pm 2.00^{b}$ \\
\hline $\begin{array}{l}\text { Genel beğeni } \\
\text { Overall appreciation }\end{array}$ & $6.61 \pm 1.96^{a}$ & $5.38 \pm 2.19^{b}$ & $5.26 \pm 2.21^{b}$ & $4.99 \pm 2.25^{b}$ \\
\hline
\end{tabular}

\section{Sonuçlar}

Nane distilasyon yan ürünlerinden birisi olan hidrosoller, bitkilerden uçucu yağ elde edilmesi sonrasında oluşan ikincil ürünlerdir ve içerdiği fenolik bileşikler sayesinde eklendiği çeşitli ürünlere biyoaktif bileşenler kazandırabilirler. Kurutulmuş formda nane hidrosollerinin formülasyonlara dahil edilmesinin antioksidan aktivitede olumlu katkılar sağlayarak ürünlerin işlevsel özelliklerini önemli derecede artırdığı belirlenmiştir. Hidrosollerin kurutulması işlemiyle bu değerli bileşenlerin korunması sağlanarak ürünlerin zenginleştirme işlemi gerçekleştirilmiştir.
KHE ile formüle edilen ürünlerden \% 1.5 KHE içeren ürünlerin kontrol grubu ürünlerinden anlamlı şekilde $(p<0.05)$ daha yüksek toplam fenolik ve toplam flavonoid içererek daha iyi antioksidan aktivite sergilemişlerdir. KHE, dondurma ve kek formülasyonlarına dahil edilerek daha fazla biyoaktif bileşenler ve daha etkili antioksidan aktivite sağlayan ürünler elde edilmiştir. Böylece, KHE ile zenginleştirilmiş kek üretilerek başarılı yeni bir formülasyon geliştirilmiştir.

\section{Ekler}

Bu çalışma Erciyes Üniversitesi Bilimsel 
Araştırma Projeleri Birimi [proje no: FYL-20177037] tarafından desteklenmiştir.

Bu çalışma Serap BERKTAŞ' ın 'Nane (Mentha piperita L.) Distilasyonu Sonrası Suda Çözünen Materyalin Geri Kazanımı ve Materyallerin Dondurma ve Kek Üretiminde Kullanımı' adlı yüksek lisans tezinden üretilerek hazırlanmıştır.

\section{Kaynaklar}

Açu, M. (2014). Fonksiyonel Özellikleri Geliştirilmiş Dondurma Üretimi. Ege Üniversitesi Fen Bilimleri Enstitüsü Süt Teknolojisi Anabilim Dalı, Yüksek Lisans Tezi, İzmir.

Aliyev, C. (2006). Kefir ve Yaban Mersininin Dondurmanın Fizikokimyasal, Duyusal ve Mikrobiyolojik Özelliklerine Etkisi. Ondokuz Mayıs Üniversitesi Fen Bilimleri Enstitüsü Gıda Mühendisliği Anabilim Dalı Yüksek Lisans Tezi, Samsun.

Alrefaire, S. ve Bostan, K. (2017). Effect Of Clove and Lemongrass Essential Oils as Natural Antioxidants on Cake Shelf Life. Aydın Gastronomy, 1(2), 1-15.

Baltacıoğlu, C. ve Uyar, M. (2017). Kabak (Cucubita pepo L.) Tozunun Kek Üretiminde Potansiyel Kullanımı ve Kek Kalite Parametrelerine Etkisi. Akademik Gıda, 15(3), 274-280. doi:10.24323/akademik-gida.345267

Brand-Williams, W., Cuvelier, M. E. ve Berset, C. (1995). Use of a Free Radical Method to Evaluate Antioxidant Activity. Lebensm.-Wiss. u.-Technol., 28, 25-30.

Çam, M., Erdoğan, F., Aslan, D. ve Dinç, M. (2013). Enrichment of Functional Properties of Ice Cream with Pomegranate By-products. Journal of Food Science, 78(10), C1543-C1550. doi:10.1111/1750-3841.12258

D’Amato, S., Serio, A., López, C. C. ve Paparella, A. (2018). Hydrosols: Biological activity and potential as antimicrobials for food applications. Food Control, 86, 126-137. doi:10.1016/j.foodcont.2017.10.030

Drabińska, N., Ciska, E., Szmatowicz, B. ve Krupa-Kozak, U. (2018). Broccoli by-products improve the nutraceutical potential of gluten-free mini sponge cakes. Food Chemistry, 267(February 2017), 170-177. doi:10.1016/j.foodchem.2017.08.119

Dualı, G. (2010). Bazı Türk Nane (Mentha L.) Uçucu Yağlarının Biyolojik Aktiviteleri. Anadolu Üniversitesi Sağlık Bilimleri Enstitüsü Farmakognozi Anabilim Dalı Yüksek Lisans Tezi, Eskişehir.

Fleisher, A. ve Fleisher, Z. (1991). Water-Soluble Fractions of The Essential Oils. Perfumer and Flavorist, 16, 37-41.

Gómez, M., Oliete, B., Rosell, C. M., Pando, V. ve Fernández, E. (2008). Studies on cake quality made of wheatchickpea flour blends. LWT - Food Science and Technology, 41(9), 1701-1709. doi:10.1016/j.Iwt.2007.11.024

Jeong, K. M., Jin, Y., Yoo, D. E., Han, S. Y., Kim, E. M. ve Lee, J. (2018). One-step sample preparation for convenient examination of volatile monoterpenes and phenolic compounds in peppermint leaves using deep eutectic solvents. Food Chemistry, 251, 69-76. doi:10.1016/j.foodchem.2018.01.079

Kamiloglu, S., Ozkan, G., Isik, H., Horoz, O., Van Camp, J. ve Capanoglu, E. (2017). Black carrot pomace as a source of polyphenols for enhancing the nutritional value of cake: An in vitro digestion study with a standardized static model. LWT-Food Science and Technology, 77, 475-481. doi:10.1016/j.Iwt.2016.12.002

Kim, J. H., Lee, H. J., Lee, H. S., Lim, E. J., Imm, J. Y. ve Suh, H. J. (2012). Physical and sensory characteristics of fibreenriched sponge cakes made with Opuntia humifusa. LWT - Food Science and Technology, 47(2), 478-484. doi:10.1016/j.Iwt.2012.02.011

Li, Y., Guo, C., Yang, J., Wei, J., Xu, J. ve Cheng, S. (2006). Evaluation of antioxidant properties of pomegranate peel extract in comparison with pomegranate pulp extract. Food Chemistry, 96(2), 254-260. doi:10.1016/j.foodchem.2005.02.033

Lu, T. M., Lee, C. C., Mau, J. L. ve Lin, S. D. (2010). Quality and antioxidant property of green tea sponge cake. Food Chemistry, 119(3), 1090-1095. doi:10.1016/j.foodchem.2009.08.015

Mau, J. L., Lee, C. C., Chen, Y. P. ve Lin, S. D. (2017). Physicochemical, antioxidant and sensory characteristics of chiffon cake prepared with black rice as replacement for wheat flour. LWT - Food Science and Technology, 75, 434-439. doi:10.1016/j.Iwt.2016.09.019

Pasukamonset, P., Kwon, O. ve Adisakwattana, S. (2016). Alginate-based encapsulation of polyphenols from Clitoria ternatea petal flower extract enhances stability and biological activity under simulated gastrointestinal conditions. Food Hydrocolloids, 61, 772-779. doi:10.1016/j.foodhyd.2016.06.039

Rajeswara Rao, B. R. (2013). Hydrosols and Water-Soluble Essential Oils: Medicinal and Biological Properties. Recent Progress in Medicinal Plants. Essential Oils I, 36(1), 120-140.

Re, R., Pellegrini, N., Proteggente, A., Pannala, A., Yang, M. ve Rice-Evans, C. (1999). Antioxidant activity applying an improved ABTS radical cation decolorization assay. Free Radical Biology and Medicine, 26(9-10), 12311237. doi:10.1016/S0891-5849(98)00315-3

Sakiyan, O., Sumnu, G., Sahin, S., Meda, V., Koksel, H. ve Chang, P. (2011). A Study on Degree of Starch Gelatinization in Cakes Baked in Three Different Ovens. Food and Bioprocess Technology, 4(7), 12371244. doi:10.1007/s11947-009-0210-2

Shin, J. H., Choi, D. J. ve Kwon, O. C. (2007). Physical and Sensory Characteristics of Sponge Cakes Added Steamed Garlic and Yuza Powder. Korean Journal of Food and Nutrition, 20(4), 392-398.

Singleton, V. L. ve Rossi, J. A. (1965). Colorimetry of total phenolics with phosphomolybdic-phosphotungstic acid reagents. American Journal of Enology and Viticulture, 16, 144-158.

Sinha, R. ve Chattopadhyay, S. (2011). Changes in the leaf proteome profile of Mentha arvensis in response to Alternaria alternata infection. Journal of Proteomics, 74(3), 327-336. doi:10.1016/j.jprot.2010.11.009

Zhishen, J., Mengcheng, T. ve Jianming, W. (1999). The determination of flavonoid contents in mulberry and their scavenging effects on superoxide radicals. Food Chemistry, 64(4), 555-559. doi:10.1016/S03088146(98)00102-2 